\title{
Nurses Knowledge Assessment for Anterior Cruciate Ligament Surgery at Assiut University Hospital
}

\author{
Hussien., Sh., A., Ahmed., M., A, H., \& El-kady., H., A. \\ Medical-Surgical Nursing, Faculty of Nursing, Assiut University. \\ Medical-Surgical Nursing, Faculty of Nursing, Assiut University. \\ Orthopaedic-Surgical Medicine, Faculty of Medicine, Assiut University.
}

\begin{abstract}
:
Anterior Cruciate ligament (ACL) surgery is one of the most common clinical entities in daily orthopaedic practice. The Aim of the study is to assess nursrs knowledge and practice for patients with ACL surgery. Quasi experimental research design was utilized in this study .This study was conducted in arthroscopy and sports injuries unit at orthopaedic department at Assiut University Hospital. A convenient sample of all available nurses (44 nurses) was included in this study. Data collected by utilizing the designed interview questionnaire sheet consists of biosocial characteristics of nurses, assessment of nurses's knowledge, observation checklist sheet to assess nurses's practice. The results can be concluded that (93.2) of nurses had an poor level of knowledge regarding ACL, all of nurses (100\%) had an inadequate level of practice regarding patients who had ACL surgery. It was found that there was a strong relationship $(\mathrm{r}=.838, \mathrm{P}=.0001)$ between total knowledge and total practice. Conclusion: Nurses`s knowledge and practice regarding patient who had ACL surgery in orthopaedic department of Assiut University Hospitals are unsatisfactory and inadequate. Recommendation :All nurses need to develop nursing care standards for patients with ACL surgery to improve nurses` knowledge and practice
\end{abstract}

\section{Introduction}

The anterior cruciate ligament(ACL) injury more commonly causes knee instability than does injury of other knee ligaments (Arnheim etal, 2011). estimated 200,000 (ACL-related injuries occur annually in the United States (Brophy RH ,et al.2009).In the last year $(1 / 1 / 2011-1 / 1 / 2012)$, approximately 247 cases admitted to the orthopedic department of Assiut University Hospital (Assiut University Hospital Record,2011-2012).

Assessment of nurse knowledge and practice is very important in the health care system because changes in the health care brought about by scientific developments have and will continue to greatly influence the education, theory and practice of nursing as in other health professions (American association of neuroscience nurses, 2012). Nursing, therefore, must continue to examine its practice in the face of these developments in order to ensure that its practice is in consonance with global nursing standards and the satisfaction of its patients in order to maintain its relevance in the healthcare industry and the society (Ijeoma, et al, 2011).

There are many ways the ACL can be torn, the most prevalent is when the knee is bent too much toward the back and when it goes too far to the side .Tears in the ACL ligament often take place when

the knee receives a direct impact from the front of the thigh while the leg is in astable position, for example astanding football player

is tackled sideways when his feet are firmly planted (Langran ,2010 )
ACL tear can be diagnosed by a popping sound heard after impact, swelling after a couple of hours, severe pain when bending the knee, and when the knee buckles or locks during movement or giving way while standing still with weight on the affected knee (Amy and Micheo , 2010), Also, the pivot-shift test, anterior drawer test and the Lachman's test are used during the clinical examination of suspected ACL injury. The ACL can also be visualized using a magnetic resonance imaging scan (GuillodoY, etal, 2008).

Treatment for ACL rupture may be conservative or surgical. Conservative management often includes physical therapy and using a knee brace.For patients who frequently participate in such sports, surgery is often indicated (Amy, 2011).

ACL injury severely limits knee movement and can affect daily activities and quality of life so, the nurse should provide care to help this patient to improve the patients' condition, reducing or preventing postoperative complications, and improve patients general health (Taylor, 2008).

\section{Aim of the study}

The aims of the study was to assess nurse knowledge and practice regarding patients who had anterior cruciate ligament surgery .

\section{Subjects and Methods \\ Research design}

Quasi experimental research design. 


\section{Setting:}

The study was conducted in the unit of Arthroscopy and sport injuries in Assiut University Hospital.

\section{Subjects:}

A convenience sample of all available nurses (44) working in orthopedic surgery department and who are willing to participate in this study.

\section{Study tools:}

Tool I: Interview questionnaire sheet: it was designed by the researcher based on current and international literature to assess nurses' knowledge regarding ACL injury and it consists of two parts:

Part (1): Sociodemographic characteristics of nurses: it includes age, gender, marital status, qualification, years of experience, and previously attended training programs about ACL injury .

Part (2): Assessment of nurses' knowledge: it includes definition ,causes, immediate signs, immediate treatment of ACL injury, complication, nursing care, instruction after ACL injury.

Tool II: Observation checklist sheet: it was designed by the researcher after reviewing of literature to assess nurses' practice. It was included two parts:

Part (1): nurses' practices: it includes vital signs, neurovascular assessment , CPM device ,ROM exercise.

Part (2):patient instructions: it includes information about crutches , cold application ,knee brace ,knee immobilizer ,possible complication ,post operative instruction .

\section{Scoring system:}

For interview questionnaire: the total scores of questionnaire 27 grades, one grade was given for the correct answer and zero for the incorrect answer. Those who obtained less than $(50 \%)$ were considered having poor level of knowledge. (50\%) were considered having satisfactory level of knowledge and above were considered having good level of knowledge.

For observation checklist: the total scores of performance checklist 480 grades, Those who obtained less than $(50 \%)$ were considered having inadequate level of practice. Above (50\%) were considered having adequate level of practice.

\section{Methods:}

\section{Technique for data collection}

- An official permission to conduct the study was obtained by the researcher from the head of the Orthopaedic department and Sports injury unit . Oral consent for voluntary participation was obtained from each nurse and the nature and purpose of the study was described. The researcher emphasized that the participation is voluntary, confidentiality and anonymity of the subjects was assured through coding of all data.

-Validity of tools was done by 5 experts. By the end of this phase, a pilot study was carried out on $10 \%$ of sample to test the feasibility of the study and applicability of the tools, and the time needed to complete the tool was 15 minutes. After pilot study, the tool was used.

-Data collection was carried out from 14 "February 2012 until 14 "May 2012.The interview questionnaire sheet was filled by the researcher while the nurses were on duty; purpose of the study was explained prior to get the questionnaire' questions asked. Each nurse involved in the study was interviewed to answer the questionnaire' questions. Observation checklist for nurses carried out during the morning and afternoon shift.

Analysis of date:

The collected data were coded then transformed into specially designed form so as to be suitable for entering into IBM compatible computer. All entered data were verified for any errors using Statistical Package for Social Sciences (SPSS) version 16 for windows. Descriptive statistics as number, percentage, mean and standard deviation. Data were collected, tabulated and statistically analyzed using Chi-square test, t-test, and ANOVA test. Correlation coefficient ( $r$ ) was calculated between continuous variables.

Table (1): Distribution of study sample according to socio demographic characteristics of nurses.

\begin{tabular}{|c|c|c|}
\hline Variables & No. $(n=44)$ & $\%$ \\
\hline \multicolumn{3}{|l|}{ Age: (years ) } \\
\hline$<30$ & 17 & 38.6 \\
\hline $30-<40$ & 15 & 34.1 \\
\hline$\geq 40$ & 12 & 27.3 \\
\hline Mean \pm SD (Range) & \multicolumn{2}{|c|}{$\begin{array}{l}33.20 \pm 9.26(19- \\
54)\end{array}$} \\
\hline \multicolumn{3}{|l|}{ Sex: } \\
\hline 1. Male & 8 & 18.2 \\
\hline 2. Female & 36 & 81.8 \\
\hline \multicolumn{3}{|l|}{ Marital status: } \\
\hline 3. Single & 8 & 18.2 \\
\hline 4. Married & 35 & 81.8 \\
\hline 5. Divorced & 1 & 2.3 \\
\hline \multicolumn{3}{|l|}{ Qualification: } \\
\hline $\begin{array}{l}\text { 6. Nursing } \\
\text { diploma }\end{array}$ & 34 & 77.3 \\
\hline $\begin{array}{l}\text { 7. } \quad \text { Technical } \\
\text { Nursing Institute }\end{array}$ & 7 & 15.9 \\
\hline $\begin{array}{l}\text { 8. Nursing } \\
\text { Bachelor }\end{array}$ & 3 & 6.8 \\
\hline
\end{tabular}




\begin{tabular}{|l|c|c|}
\hline \multicolumn{1}{|c|}{ Variables } & No. $(\mathbf{n}=\mathbf{4 4})$ & \% \\
\hline \multicolumn{1}{|c|}{ Years of experience: } & \multicolumn{1}{|c|}{} \\
\hline$<10$ years & 17 & 38.6 \\
\hline $10-<20$ & 15 & 34.1 \\
\hline$\geq 20$ & 12 & 27.3 \\
\hline $\begin{array}{l}\text { Previously attended } \\
\text { training programs } \\
\text { about ACL injury: } \\
\text {-Yes }\end{array}$ & & \\
-No & - & - \\
\hline
\end{tabular}

This table shows that mean of age of nurses was $(33.20 \pm 9.26)$, more half of nurses were $<30$ years old ,female ,married ,nursing diploma , and $<10$ years of experience .Finally this table discuss that all of nurses $(100 \%)$ not attending any previous training program about anterior cruciate ligament injury.

Table (2): Distribution of study sample according to the level of nurses` practice $(n=44)$.

\begin{tabular}{|c|c|c|}
\hline \multirow[b]{2}{*}{ Practices } & \multicolumn{2}{|l|}{$(n=44)$} \\
\hline & No. & $\%$ \\
\hline Adequate & 0 & 0.0 \\
\hline Inadequate & 44 & 100.0 \\
\hline
\end{tabular}

This table discuss that all control group (100\%) have inadequate level of practice .

Table (3): Distribution of study sample according to the level of knowledge $(n=44)$.

\begin{tabular}{|l|l|l|}
\hline \multirow{2}{*}{ Knowledge } & \multicolumn{2}{|c|}{$\begin{array}{c}\text { Control group } \\
(\mathbf{n}=\mathbf{4 4})\end{array}$} \\
\cline { 2 - 3 } & No. & \% \\
\hline Good & - & - \\
\hline Satisfactory & 3 & 6.8 \\
\hline Poor & 41 & 93.2 \\
\hline
\end{tabular}

- = Not Applicable

This table shows that the $6.8 \%$ of control group knowledge were satisfactory, $93.2 \%$ were poor.

Table (4): Distribution of study sample according to total mean score of nurses knowledge and practice.

\begin{tabular}{|l|l|}
\hline Variable & mean \pm S.D \\
\hline Nurses` knowledge & $7.57 \pm 2.73$ \\
\hline Nurses` practice & $133.07 \pm 30.60$ \\
\hline
\end{tabular}

This table enumerate that nurses` knowledge was7.57 \pm 2.73 and nurses practice was $133.07 \pm$ 30.60 .

Table (5): Relation between score of knowledge and socio-demographic characteristics

\begin{tabular}{|c|c|c|c|}
\hline Variables & Mean \pm SD & Range & P-value \\
\hline \multicolumn{3}{|l|}{ Age: (years ) } & \multirow{4}{*}{$0.002 *$} \\
\hline$<30$ & $6.18 \pm 1.42$ & $3-8$ & \\
\hline $30-<40$ & $7.60 \pm 2.56$ & $4-15$ & \\
\hline$\geq 40$ & $9.50 \pm 2.94$ & $5-14$ & \\
\hline \multicolumn{3}{|l|}{ Sex: } & \multirow{3}{*}{$0.001 *$} \\
\hline Male & $11.75 \pm 2.49$ & $9-15$ & \\
\hline Female & $6.64 \pm 1.53$ & $3-9$ & \\
\hline \multicolumn{3}{|l|}{ Marital status: } & \multirow{3}{*}{$0.003 *$} \\
\hline Single & $5.13 \pm 1.36$ & $3-7$ & \\
\hline Married & $8.11 \pm 2.54$ & $4-15$ & \\
\hline \multicolumn{3}{|l|}{ Qualification: } & \multirow{3}{*}{0.060} \\
\hline Diploma & $7.97 \pm 2.75$ & $3-15$ & \\
\hline Institute/ Bachelor & $6.20 \pm 1.62$ & $4-9$ & \\
\hline \multicolumn{3}{|c|}{ Years of experience: } & \multirow{4}{*}{$0.001 *$} \\
\hline$<10$ years & $5.82 \pm 1.42$ & $3-8$ & \\
\hline $10-<20$ & $7.80 \pm 1.21$ & $5-10$ & \\
\hline$\geq 20$ & $9.75 \pm 3.49$ & $5-15$ & \\
\hline
\end{tabular}

The table reveal that in relation between score of knowledge and socio-demographic characteristics no statistical difference related to qualification. 
Table (6) Relation between score of practices and socio-demographic characteristics

\begin{tabular}{|c|c|c|c|}
\hline Variables & Mean \pm SD & Range & P-value \\
\hline \multicolumn{3}{|l|}{ Age: (years ) } & \multirow{4}{*}{0.083} \\
\hline$<30$ & $129.29 \pm 27.05$ & $86-176$ & \\
\hline $30-<40$ & $124.27 \pm 30.77$ & $68-176$ & \\
\hline$\geq 40$ & $149.42 \pm 31.17$ & $94-182$ & \\
\hline \multicolumn{3}{|l|}{ Sex: } & \multirow{3}{*}{0.985} \\
\hline Male & $133.25 \pm 28.65$ & $93-176$ & \\
\hline Female & $133.03 \pm 31.40$ & $68-182$ & \\
\hline \multicolumn{3}{|l|}{ Marital status: } & \multirow{3}{*}{0.593} \\
\hline Single & $127.75 \pm 32.49$ & $86-174$ & \\
\hline Married & $134.25 \pm 30.52$ & $68-182$ & \\
\hline \multicolumn{3}{|l|}{ Qualification: } & \multirow{3}{*}{0.655} \\
\hline Diploma & $134.21 \pm 29.38$ & $68-182$ & \\
\hline Institute/ Bachelor & $129.20 \pm 35.89$ & $86-182$ & \\
\hline \multicolumn{3}{|c|}{ Years of experience: } & \multirow{4}{*}{0.302} \\
\hline$<10$ years & $128.41 \pm 27.03$ & $86-176$ & \\
\hline $10-<20$ & $128.93 \pm 30.86$ & $68-182$ & \\
\hline$\geq 20$ & $144.83 \pm 34.32$ & $93-182$ & \\
\hline
\end{tabular}

The table shows that no statistical difference in relation between score of practices and socio-demographic characteristics in all items.

Fig. (1): Correlation between score of knowledge and score of practices

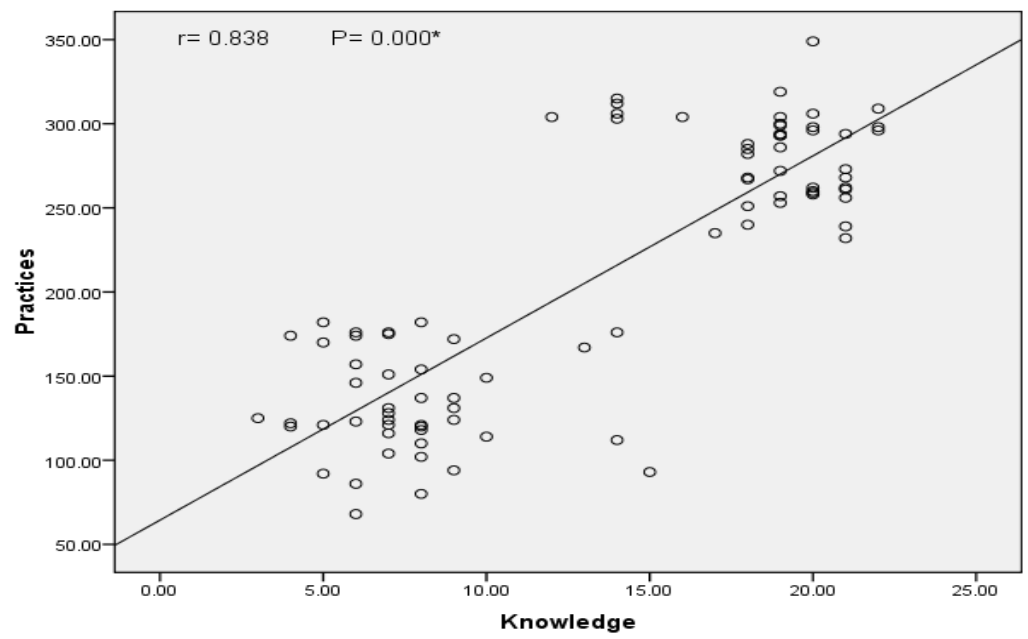

\section{Discussion}

The anterior cruciate ligament (ACL) is one of the most commonly injured ligaments of the knee. The incidence of ACL injuries is currently estimated at approximately 200,000 annually, with 100,000 ACL reconstructions performed each year. Anterior cruciate ligament (ACL) injury is a serious injury often resulting in hospital admission for surgery with the highest incidence seen in young adults (American academy of orthopaedic surgeon,2011).

The aims of the present study is to assess nurses' knowledge and practice regarding patients who had anterior cruciate ligament reconstruction surgery. The results of the present study showed that more than half of nurses were female, married, aged from 19 - 29 years. Nursing diploma was the highest proportion, more than half of them have an experience less than ten years and all of them have no in service training courses related to anterior cruciate ligament injury. (Bahza,2013); agree with this study findings " the majority of the nurses were married, female, nursing a diploma the highest proportion, years of experiences more than 3 years, (Mostafa, 2012); reveal that more than two third of the nurses their ages ranged from 20- $<30$ years, married, 
female, and have diploma of nursing their experiences range from 5 to 10 years. (Ahmed , 2011), found that all nurses not attended any previous training program. (Abd Al-Magid, 2011) ;found that more half of nurses not attended any previous training program, .(Elmasry , 2012) ; in the same line with the current study illustrated that approximately all of nurses not attended any previous training program, (Mostafa, 2012); reveal that more than two third of the nurses attended previous training program.

As regard level of knowledge ,the study obvious that approximately all of nurses have poor level of knowledge ,This result is agree with (Ahmed, 2011); who conducted a study reveal that most of nurses had unsatisfactory level of knowledge .

This result also disagreed with ( Mostafa , 2012); who conducted a study illustrated that more than two third of nurses had fair level of knowledge and minority of nurses had poor level of knowledge .

In my opinion poor level of knowledge in this study due to books that were given to the nurses during their secondary learning years were taken from them at the end of years and there is no Arabic source for updating and continuing their education. Also this may be attributed to lack of continuous education and absence of in-service training program.

The current study showed inadequate total practice scores in all items .( Ahmed , 2011), found that all nurses heve inadequate practice. (Youssef, 2007), in the same line with the current study findings revealed that nurse's practice were inadequate .However (Hassan ,2011) ; was disagree with the current study and revealed that the most nurses had adequate practice.(Elmasry , 2012); in the same line with the current study illustrated that practice obtained by nurses were inadequate .

In the present study there is relation between knowledge and socio-demographic characteristics , ( Ahmed , 2011) ; found that no relation between knowledge and socio-demographic characteristics. (Elmasry , 2012) ; in the same line with the current study reveal that no relation between knowledge and socio-demographic characteristics.

There is also no relation between practice and sociodemographic characteristics. (Ahmed , 2011) ; found that no relation between practice and sociodemographic characteristics. .(Elmasry , 2012) ; in the same line with the current study reveal that no relation between practice and socio-demographic characteristics.

As regard correlation between score of knowledge and score of practices there is positive correlation between score of knowledge and score of practices .(Elmasry , 2012) ; in the same line with the current study reveal that there is positive correlation between score of knowledge and score of practices.

\section{Conclusion:}

Nurses' knowledge and practice are unsatisfactory, inadequate regarding ACL injury in Orthopaedic department at Assiut University Hospitals.

\section{Recommendations:}

Based on the finding of this study, following recommendations were made:

- Continuous education and in-service training programs should be conducted at Orthopaedic department to improve nurses' knowledge and practice regarding ACL injury in Orthopaedic department at Assiut University Hospitals.

-Develop standards of nursing care for patients with anterior cruciate ligament reconstruction surgery .

\section{References:}

1. Abd-Al-Mageed, A.S, (2011): Nursing care standards for cancer patient undergoing chemotherapy at Assuit University Hospital .thesis Submitted for Partial Fulfilment of the Requirement of the Doctorate Degree in Medical Surgical Nursing ,faculty of nursing Assiut University ,discussion part,pp.112-115.

2. Ahmed, R.A(2011) : Developing nursing care standards for patient with chronic suddural haematoma at Assuit University Hospital .thesis Submitted for Partial Fulfilment of the Requirement of the Master Degree in Medical Surgical Nursing ,faculty of nursing Assiut University ,discussion part,pp.57-58.

3. American academy of orthopedic surgeon, (2011): Available at: http:// orthoinfo.aaos.org/topic.cfm?topic $=$ A00297.

4. American association of neuroscience nurses (2012): neuroscience nursing: scope and standards of practice, 4th ed., and p.7-23

5. Amy E,S.H,(2011): Knee Sprain http://pediatrics.med.nyu.edu/conditions-wetreat/conditions/knee-sprain

6. Amy E, Micheo W, (2010):Anterior cruciate ligament tear. Essentials of Physical Medicine and Rehabilitation. 2nd ed. Philadelphia, Pa: Saunders Elsevier;: chap 55.

7. Assiut University

Hospital Record,Orthopaedic department, Arthroscopy and sports injuries unit ( 2011-2012).

8. Bahza,N.M (2013) :Developing nursing care standards for patient with colostomy at Assuit University Hospital thesis Submitted for Partial Fulfilment of the Requirement of the Master 
Degree in Medical Surgical Nursing ,faculty of nursing Assiut University ,discussion part,pp.5758.

9. Brophy RH, Wright RW, Matava MJ, (2009): Cost analysis of converting from single-bundle to double-bundle anterior cruciate ligament reconstruction. Am J Sports Med. 2009 Apr; 37(4):683-7.

10. Elmasry_M.A ( 2012): Effect of designed nursing protocol on nurses knowledge and practice regarding epileptic patient at Assuit University Hospital .thesis Submitted for Partial Fulfilment of the Requirement of the Master Degree in Medical Surgical Nursing ,faculty of nursing Assiut University ,Discussion part,pp0883

11. Guillodo Y, Rannou N, Dubrana F, Lefèvre C, Saraux A, (2008): Diagnosis of anterior cruciate ligament rupture in an emergency department. $J$ Trauma. Nov 2008; 65(5):1078-82.

12. Hassan.G,H (2011)_:Effect of designed nursing protocol on nurses knowledge and practice regarding hemodialysis patient at Assuit University Hospital thesis Submitted for Partial Fulfilment of the Requirement of the Master Degree in Medical Surgical Nursing ,faculty of nursing Assiut University ,result part,p58.

13. Ijeoma,E.O.\& Ada, N.\& Peace, I.\& Akpati, V. (2011): Helpless patients 'satisfaction with quality of nursing care in Federal tertiary hospitals , Enugu , Southeast, Nigeria. International Journal:6-13

14. Langran, (2010):Alpine Ski Injuries. SkiInjury.com. http://www.ski-injury.com/specificsports/alpine. Retrieved 5 December

15. Mostafa, (2012): Developing standards of postoperative nursing interventions for lower limb amputated patients

16. Taylor C., (2008): Fundamentals of Nursing: The Art and Science of Nursing Care, $6^{\text {th }}$ ed., Philadelphia: Lippincott Williams and Wilkins

17. Youssef, S.S., (2007): Micro vascular free tissue transfer surgeries, Impact of a designed teaching protocol on nurse's knowledge, practices and patient's outcome. Submitted for fulfillment of the requirements of Doctorate Degree in Adult Nursing, Faculty of Nursing, and Assiut University. 